\title{
Introduce the Result - oriented Concept to Reform the ASP.NET Course
}

\author{
Fenjuan Yu \\ Shaanxi Institute of Technology, Xi'an, 710300,China,
}

Keywords: Results-oriented, Integration of Doing, Learning and Teaching, Fine Stresses Rhetoric, Project Teaching

\begin{abstract}
The introduction of results-oriented educational philosophy, strengthen the practice, the use of task-driven "ASP.NET application development" curriculum reform and practice, so that students in the process of completing specific projects to build the relevant theoretical knowledge and develop professional skills, both improve the students' interest in learning, but also in line with the characteristics of higher vocational classroom teaching, more importantly, through the implementation of "fine stresses hard training, through the project" comprehensive training, comprehensively improve the student's software development capabilities.
\end{abstract}

\section{Introduction}

Outcome based education (OBE) is a kind of new educational method which is produced under the influence of the western and western vocational education ideas. It is the international advanced education method. The concept is student-centered, results-oriented, to promote the focus of education and teaching reform from the emphasis on resource investment into the emphasis on student learning outcomes, so that everyone can learn. Core thinking on the students "learned what" school, teachers "teach what". This is the character and the concept of vocational education in China, that is, by cultivating students' practical ability and sustainable development ability, to promote the overall improvement of student skills.

"ASP.NET application development" curriculum theory knowledge points, scattered cases, there are a lot of computer language and rules and rules, the use of traditional teaching methods, learning process boring, students generally feel abstract. And the introduction of results-oriented educational philosophy, through the implementation of "fine stresses through the project" comprehensive training, classroom test results are obvious and students do secondary school, learned the development of the network technology, access to the results of the experience and promote the learning ability.

\section{The Confusion of ASP.NET Course Traditional Teaching}

The Confusion Caused by the Status Quo of the Students Source. With the increasing pressure of enrollment, vocational colleges generally adopt both literary and artistic income, students are very common differences. The traditional way of teaching is the teacher to take into account the majority of students to accept the extent of the first arrangement of teaching content analysis and finishing, and then step by step to teach the relevant knowledge points, and then introduce examples of skilled knowledge of their knowledge, the result is not only good students to eat Not enough, the poor students have anorexia. This kind of teaching not only students are not satisfied, but also is not conducive to the cultivation of engineering ideas, students learn something difficult and business docking, employment is difficult to guarantee.

The Confusion Caused by the Traditional Teaching Model. ASP.NET programming courses are generally used in four multimedia theory teaching plus 2 room practice. Theoretical teaching in the multimedia classroom, teachers tend to attach importance to basic knowledge, technical principles, students in the learning process is difficult to understand the knowledge of the chapters 
in real life or tracking system development case relevance, and thus gradually lost interest in learning. More importantly, in the multimedia classroom students to see the teacher is constantly demonstrated, but not the same time the operation of interaction, is not conducive to the teacher's scene and the interaction between teachers and students.

After the end of the multimedia class, students tend to focus on learning a large amount of theoretical knowledge, and the development of practical projects are not involved, coupled with the actual operation of the room may be more time from the multimedia theory class time, when many students cannot complete the project development tasks cannot successfully complete the operation, seriously affecting the quality of teaching.

The Confusion Caused by the Re-Theory of the Assessment Model. The traditional assessment method is the end of the teaching content and the theoretical examination of qualified even finished this course. Students followed the teacher's assessment baton away, a good student to teacher before the exam review the content of a given an easy ride, but most of the theory of vocational students learning ability is poor and it is difficult to cope with both traditional rote theory examination. The results of a large area of the course failed examinations, scores are not uncommon. This only pay attention to theoretical test scores, ignoring the practice of practical ability assessment, do not meet the results-oriented educational philosophy. The result will inevitably lead students to lose interest in learning, is not conducive to the cultivation of students' ability to practice and improve.

\section{The Introduction of Results-Oriented Educational Philosophy - The Reform of ASP.NET Classroom Teaching Form}

Achievement-oriented education is an education system that emphasizes ability training and ability training. Teachers must "career-demand-oriented, innovative and practical ability as the main line, to build students 'knowledge, skills and qualities of architecture" in the teaching process, the emphasis is to explore students' personal values and potential. And ASP.NET is an object-oriented technology with a strong operational requirement.

Task-Driven ASP.NET Curriculum Reform. Based on the results of the concept of education, we need to adapt to changes in student positions, the ASP.NET project settings. As a key link of achievement-oriented teaching, it is necessary to change the teaching of knowledge-based teaching into students' ability-based teaching. It should be changed from "inculcation of classroom" to "dialogue classroom" to realize curriculum reform, classroom reform and method change. At the same time, teaching should be based on enterprise projects as a carrier, cleverly integrated curriculum knowledge points into the project teaching. Let the students "do middle school, do it in school".

In the set before the first understanding of the needs of business users, grasp the training intentions and objectives, in-depth software development enterprises to their work investigation, and then around the curriculum development projects. This is the development of integrated project courses more targeted, practical and forward-looking, but also more professional characteristics. Of course, we will have to take into account the future sustainability of our students. While noting that the software industry often has new changes and requirements, curriculum development is always in a dynamic process of change, the contents of the curriculum plan should be constantly revised and improved.

"Refined Stresses Hard Training, Through the Project" Training ASP.NET Curriculum Comprehensive Ability. Achievement - oriented education is focused on the cultivation of students' abilities. ASP.NET courses use problem-oriented learning, group cooperative learning, practical learning, simulation exercises and other teaching methods to carry out teaching, so that all students have a sense of accomplishment.

The implementation of "fine stresses rhetoric, task-led, project-driven" teaching model, to build, learn, teach one of the teaching environment, to achieve "do, learn, teach one" room teaching. The school has a special project schedule and dedicated room. According to the project grouping of students, and task-driven teaching, project teaching, case teaching, hierarchical teaching and other 
teaching methods combined to form a three-dimensional teaching system.

In order to reflect the practicality of this course, for beginners, such as: registration, registration, teachers guide students to write code and explain in detail, students hot iron, copy to achieve, with the participation of teachers and students, so that students have a sense of accomplishment. At this time, let the students themselves to analyze the login interface design contains what controls, the interface to be connected to the database after the specific sql statement; finally, the teacher prompts the students to see their favorite web page design style, the interface and then processing design more personalized. Therefore, step by step, sub-level to complete a number of projects, and to complete the situation, teachers should track in time to understand the overall situation of each group, so that each group of students have learned to encourage poor students to complete the design, Students encourage their innovation, do more exploration, let them participate in the actual project.

\section{Strengthen the Assessment Process and Implementation of Diversified Evaluation}

Achievement-oriented education is student-centered, capacity-based, emphasizing that every student has the ability to advocate everyone can succeed, learning should be based on cooperation rather than competition, schools and teachers to provide students with clear and clear learning results blueprint and create opportunities and the environment for students to succeed. Evaluation of the effect of teaching reform should not only focus on assessing students 'learning process, but also to highlight the assessment of students' practical abilities, students should focus on vocational training, learning, innovation, teamwork assessment. Therefore, a wide range of teaching objectives and a variety of teaching and learning methods determine the assessment must be implemented diversification.

The whole process of ASP.NET curriculum assessment model achieve three-dimensional, standardized, full. Assessment and evaluation consists of two parts, the process assessment accounted for $50 \%$ and the final assessment accounted for $50 \%$. In the two parts of the process assessment is divided into four parts, including the attitude (10\%), ask questions (5\%), training reports (15\%), learning achievement assessment (20\%); final examination in two parts: (15\%), operation (35\%).

Through three rounds of ASP.NET curriculum reform, we have helped students to build a good knowledge system, at the same time in teaching has achieved good results, students learn the enthusiasm, initiative has been improved, students practical ability, comprehensive quality, team Collaborative ability to get a good exercise, to "do secondary school, teach to do" a good atmosphere. The achievement of these achievements proves that our reform program is valid. It has a positive reference value for other information curriculum reform in higher vocational colleges. At the same time, we take a combination of voluntary and teacher choice in the campus, select some good students to participate in the creation and research of software studios, For the future selection of the contest to prepare, but also to do, learn, teach, research integration to achieve the preparation.

\section{References}

[1] Li Xianfeng Achievement - oriented educational philosophy of learning research[J]. Career Research 2015.07

[2] Meng Chong, Zhou Kun, Zhou Min, Jiang Haihong. Vocational education ASP.NET curriculum diversification of teaching reform research[J]. Agricultural Network Information, 2015 the first 11

[3] Wang Fuhuan, Yang Qi. Reform and Practice of Dynamic Web Development Course Based on ASP.NET[J]. Journal of Wuhu Vocational and Technical College, 2014 (2)

[4] Wang Cuixiang, Shao Xing, Sun Ganchao. ASP.NET course teaching reform research and practice [J]. Software Guide 16, No. 4 (April 2017) 